\title{
Promoting Harmony during Disagreements: A Portrait of Adult Discussions in the Indonesian Context
}

\author{
Zuliati Rohmah \\ IAIN Sunan Ampel Surabaya, Indonesia \\ Email: zettira@gmail.com
}

\begin{abstract}
This paper presents different strategies applied by adult students when expressing disagreements during discussions. The use of a variety of strategies by the students show that conveying disagreements is not an easy task for the academia living in a collectivist society. Responses to the disagreements are also varied, ranging from communication deadlock to partial acceptance, support, offer of an account, support from another participant, neutralizer from another participant, and acceptance. The analysis of the data shows that, in the presence of disagreements, learning is mostly facilitated by disagreements expressed through peer acknowledgment and vulnerability assertion.
\end{abstract}

Index Terms - disagreement, discussions, strategies, responses, Indonesian context

\section{INTRODUCTION}

A discussion has been characterized as a forum to negotiate meanings, messages and positions (Basturkmen, 2002; de Klerk \& Hunt, 2000; Medina, 2010; Tracy and Carjuzaa, 1993; Tracy and Baratz, 1993; Viechnicki, 1997; Webber \& Kyriacou, 2008). To achieve their goals, discussion participants apply strategies to get their messages across and to attain their intended positions (Rohmah, 2003; Waring, 2000, 2001, 2002 a \& b; Nathan, Eilam \& Kim, 2007). During discussions, students apply conversational management strategies, topic management strategies and social strategies (Waring, 2000).

Expressing disagreement is one way of showing one's intellectual stance which is different from the others' position. In an academic writing, a writer takes a position in opposition to others' work. This necessitates the evidence that others are wrong, weak in argumentation, thus, an improvement is sought. In academic settings, students are trained to evaluate other people's arguments, disprove them and then offer their own stance. Without doing this, others hardly see their contribution and their intellectual ability.

Disagreements also occur outside of academic contexts. A study by Tuval-Mashiach \& Shulman (2006), for instance, reported developmental differences in disagreement negotiation and resolution skills among adolescent and young adult romantic partners. The first group tended to have short negotiations, the latter is richer and more developed. Adolescents' resolution of disagreements was accomplished by having superficial agreements or pressure on one partner. Young adults' decision was based on the results of discussion and agreement made by the two partners.

People apply strategies in expressing disagreements (Jacobs, 2002) since tension might occur "between preference for agreement, common to conversation, and the expectation that there will be conflicting opinions in a discussion which is a system of public accountability" (Webber \& Kyriacou, 2008, p. 99). In the previous studies, speakers express disagreements with two features - delaying the disagreements and stating them weakly and partially (Pomerantz, 1984; Mori, 1999; Waring, 2000 \& 2001). In Pomerantz's (1984) study, disagreements are shown through rhetorical questions, questioning repeats and statements. Furthermore, Waring's (2000 \& 2001) findings show that participants express their disagreements by employing two strategies, i.e. peer referencing and asserting vulnerability, to maintain a good cooperation and save the others' face.

The conclusion of the previous studies that a disagreement is a dispreferred response is challenged by two other studies by Blum-Kulka et al. (2002) and Kakava (2002). The two studies try to prove the reverse-a disagreement is normal. This is supported by Medina (2010, p. 4) that, "what is at the core of our normative behavior is the capacity to dissent, and that the possibility of contestation and normative negotiation is a prerequisite for rule-following." However, these do not present adequate evidence for the arguments that disagreement is not dispreferred. As Blum-Kulka et al. (2002) and Kakava (2002) demonstrate, in addition to the direct expressions of disagreements and strong disagreements, a mitigation action can still be found. This indicates that the speakers do not intend to be in a direct opposition to the addressees. The speakers still express their disagreements weakly and partially.

Thus, the studies by Blum-Kulka et al. (2002) and Kakava (2002) just strengthen the conclusion of the previous studies that a disagreement is a dispreferred response. From the existing studies, especially that of Blum-Kulka et al. (2002, p. 1576), it is apparent that ungrounded disagreements expressed blatantly block discussion on Talmudic texts 
from further collaboration among the participants. This is so because disagreeing, in Brown and Levinson's (1987) term, is considered one of the face threatening acts (FTAs). Disagreeing, intrinsically, may threaten positive face-want-if it is spoken blatantly, it shows that the speaker does not care about the addressee's feelings and wants.

The present study was designed to understand how adult students articulated their disagreements during discussions and explore the responses to disagreements conveyed in different strategies. While the studies abovementioned were mostly administered in western context, a study conducted by Webber \& Kyriacou (2008) in San Diego among nonnative speakers of English (NNE) showed particular difficulties for them to join the discussions. The present study analyzes discussions among adult NNE in the Indonesian context which tends to be characterized as a collectivist society.

\section{METHOD}

Conversational Analysis (CA) was applied to understand the data. With CA, the researcher tried to uncover disagreements and responses apparent in the discussants' utterances through detailed examination of the turn-taking and sequential structure of the discussions (Atkinson \& Heritage, 1984; Heritage \& Atkinson, 1984; Hutchby, 1998; Levinson, 1983; Sack, 1984; Schegloff, 1984; Wei, 2002).

The data were in the forms of transcriptions of students' utterances during doctorate classroom discussions in 'Topics in Foreign Language Teaching' course. This study included the whole two-hour discussion in the analysis to allow better understanding of the context of the utterances. In the discussions, the students were required to give an oral presentation on the assigned reading materials from journals or books followed by a question answer session.

The discussion participants were seven doctorate students from different parts of Indonesia. One student was from Sumatra, four students from East Java, one from East Nusa Tenggara, and another student was an Ambonesse who was teaching at a university in Menado, North Sulawesi. By observing discussions among students from different ethnic backgrounds, the researcher expected to find a variety of disagreeing strategies and diverse responses to them.

\section{RESULT}

The results show that there are different responses to disagreements expressed in different ways. These ranges from a communication breakdown as a result of an aggravated disagreement to acceptance or partial acceptance and further discussions as responses to disagreements expressed by acknowledging peers, asserting vulnerability and indirectly.

\section{A. Aggravated Disagreement}

Aggravating a disagreement is one way of expressing disagreements directly. In this strategy, the head act containing a disagreement can be seen in turn 36, "Yeah, then there is no discrimination, actually." This disagreement is strengthened by a series of questions prefacing and following the disagreement. Excerpt 1 shows the disagreement expressed intensively by Edo.

Excerpt $1(14 / 26-42)$

Ovi: ((presenting and explaining that the use of language in society shows discrimination between men and women)) 25

Edo: Bu Ovi, <do you agree with me that discrimination does exist in our society?> 26

Ovi: Yea, ya!!

Edo: Who discriminate who? ((This signals a start of a heated argument))

Who discriminate who? ((Low, weak voice to question herself; Ovi seems to be helpless, does not know what to say.

This is very interesting; the audience noisily follow the exchange between the two persons))

Edo: I would like to know your comment. Men discriminate women? (.) A: If men discriminate women, Pak Sad, Pak $\mathrm{Sad},>$ is it true $<$ for Pak S ((the professor)), Edo, and all of us here to live with the inferior. Maybe it's you who are inferior, not all women $=(($ pointing at Ovi $))$

Ovi: =It's not me=

Edo: $\underline{\text { Do }}$ we go together with those who are inferior?

Ovi: Ya, the woman who is your wife is as servant. Not as your leaders. ((laughter)) She wash your clothes, she cook your food... ((The audience are overexcited))

Edo: Bu, Ovi. I read from a: psikologi wanita, that's, that a discrimination exists because women treat men as different. ((The discussion participants comment on the discussion noisily)) To me (.) you, you, women need me to pay attention to. But, because we don't pay attention to you, you consider us, consider us discriminate women.

Ovi: I don't think so because men always chase women. Not women chase men. The ( ) is women not=

Edo: =Yeah, then there is no discrimination, actually. ((Adi laughs followed by others))

Ovi: (You just interpret this) Women are usually do the domestic, domestic work, ya. So that they have no voice in the public at all, ya. So, for example, they can make decision. Decision is always made by men, ya. This is a discrimination, ya.

Edo: ... because, this is is very stupid. Edo is very stupid, Bu Ovi. If he:: $>$ what is it $<$ try or work hard to catch for a woman, maybe, he can himself be considered intolerant. Subordinate, so stupid Edo is.

Ovi: But, that's what happens. You want a friend, but your friend should not, should not a:: comment them, should not order them. A friend=

Edo: $=$ Do you, do you= 
Ovi: who do something, take care of your business=

Edo: Frankly speaking, Bu Ovi, do you consider your husband, a: do, does your husband consider you as a servant?

Ovi: I think it is privat, ya. You can get the answer from Pak Sad ((All participants are boisterous when commenting the

argument. Finally, Ovi leaves the presentation and sits on a chair among other students to listen to the professor's

comment)).

In this long excerpt, Edo, who is an Ambonesse working as an English lecturer at a university in Menado, expresses his disagreement with Ovi who previously states that language use in society shows a discrimination between men and women in the society and hints that the discrimination is done by men. Edo cannot accept her statement. To him, a discrimination does not really exist in the society; if it does exist, it is because someone sees others as different, and the 'one' here is a woman, including the presenter.

Edo articulates his different stance from Ovi, a Javanese female student married to a Padangese gentleman, by asking a question slowly with an emphatic stress, "Bu Ovi, do you agree with me that discrimination does exist in our society?" When this is agreed by Ovi, he asks a further question, "Who discriminate who?" This low pitched question uttered in his heavy voice makes those who hear it become frightened mixed with excited feelings for not knowing what to happen next. He puts forth another question, "Men discriminate women?" by framing it that he desires her comment on the matter. He concludes turn 30 by accusing Ovi as feeling inferior than men that makes her perceive the discrimination from men. "Maybe it's you who are inferior, not all women." He does this by pointing his fingers to Ovi. Here, Edo changes his footing from talking about something academically to talking about private, individual business. This degrades the quality of the academic discussion involving rational and intellectual capacity and shifts it into a nonacademic debate exploiting emotions and feelings.

This is not all, Edo repeats his questions with another interrogation, "Do we go together with those who are inferior?" When this is responded by Ovi by raising Edo's personal matters, that is, that his wife has been his servant, "She wash your clothes, she cook your food" he stops questioning Ovi. He calms his voice and puts some accounts on his disagreement. However, this explanation is not accepted by Ovi; instead, she puts forward a reason which is not really connected to the matter being discussed. Edo then tries to offer a resolution which supports his stance, "Ya, then there is no discrimination, actually." Again, it is rejected by Ovi; although she cannot provide a good rationale for her rejection.

In his last turn in this excerpt, Edo again launches a question, "Frankly speaking, Bu Ovi, do you consider your husband, a: do, does your husband consider you as a servant?" This is the climax of the aggravating questions which make Ovi leave her 'presenter chair' without answering the question and return back to her seat among the other students.

The disagreement expressed in a series of provoking questions finally results in Ovi's desperation to respond to the accusation and questions as apparent in turn 43. After defending her position against Edo's provoking questions for several times, she finally cannot stand the pressure. She gives up, shuts herself from further discussions and chooses to leave her position as a presenter. She lets the professor take over the forum. Edo's way of expressing disagreement cannot be equalized to any politeness strategy mentioned by Brown and Levinson (1987). This is sharper than Brown and Levinson's (1987) bald on record strategy.

\section{B. Bald Disagreement}

Excerpts 2 and 3 show bald strategies applied by the students in expressing disagreements. This kind of strategy is applied to send a message with maximum efficiency. The strategy is realized following Grice's maxims - maxim of quality, maxim of quantity, maxim of relevance and maxim of manner (Grice, 2001, p. 167-168). The bald disagreements are responded by another participant's disagreement (excerpt 2) and ignorance (excerpt 3).

Excerpt $2(6 / 77)$

Ovi: What about the small part of the culture? We teach language, we teach that small part of the culture. We teach our children breakfast.

"What do you have for breakfast?" And then, this is cultural thing.

Tia: Ya, ya. [That's a small part of the culture.

Ovi: [That's a small part of the culture (.)

In excerpt 2, Tia is exchanging ideas with Koko. Tia was raised and educated in Central Java. Unlike Tia, Koko is a Sumatranese male who grew up in Lahat and Palembang. Tia expresses her disagreement with Koko by openly negating Koko that what she has just said is based on the research finding. She cancels it out by saying that the findings do not contain the information about the inevitability of teaching culture in their language teaching. She negates Koko's conclusion mainly by putting the word 'not' in her sentence. She conveys her disagreements without prefacing her expressions with any redress action or giving explanation to ground her disagreement. Thus, by her disagreement, she just expresses that what she has said is her own conclusion of the paper. 
Tia's disagreement in turn 77 is responded by Ovi by giving a rhetorical question, "What about the small part of the culture?" This is to preface her illustration that when they teach the word 'breakfast', they teach one part of a culture. Because what the western people have for breakfast is different from what the Indonesians generally have. When teaching about 'breakfast', the teacher should include the items for breakfast, and this is related to culture. Hence, Ovi responds to Tia's disagreement with Koko by putting forward her indirect disagreement through a rhetorical question.

Another disagreement expressed forthrightly without any redress action is apparent in Excerpt 3.

Excerpt $3(12 / 34)$

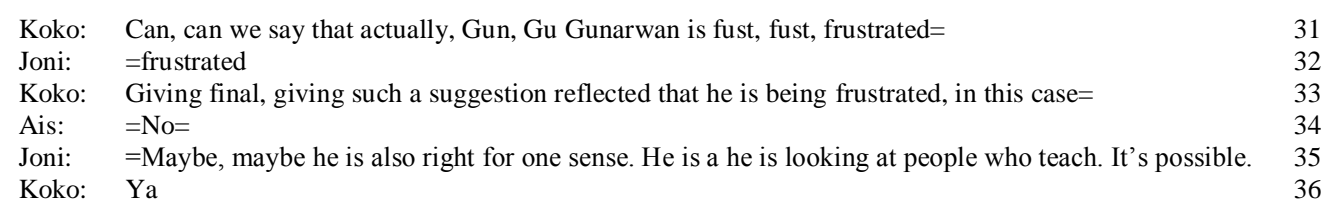

In the data above, Ais - a Malangese female student—disagrees with Koko's attribution to the author of the article being discussed. In turn 33, Koko states that the writer gives a certain suggestion mentioned in the article, with which Koko does not agree, because he is frustrated. Ais's 'no' disagreement expression contradicts straightforwardly with Koko's attribution to the writer. The disagreement is expressed in a low voice when Koko asks Joni's opinion about the writer. Thus, the 'no' expressed by Ais occurs in the background of the conversation between Koko and Joni. As the presenter, Joni tries to explain that the author might be correct in one way without offending Koko by saying that he might also be right in another way. In the middle of such a conversation, Ais expresses her disagreement with a short 'no' and does not explain it any further because she realizes that if she continues, it will disturb the conversation between Koko and Joni.

In the previous studies of disagreements, this type of disagreement is called as "ungrounded disagreement" (BlumKulka et al., 2002, p. 1576) and "un-prefaced disagreement" (Kakava, 2002, p. 1555). However, there is a slight different emphasis on the naming of the disagreement as "ungrounded disagreement" and "un-prefaced disagreement". In Blum-Kulka et al.'s "ungrounded disagreement", the speaker does not provide his/her rejection to the prior utterances with an account on why he/she disagrees with the earlier speaker. Unlike Blum-Kulka et al.'s, Kakava's "un-prefaced disagreement" is used to show disagreements expressed without any prefatory talk which may alert the addressee with the upcoming disagreement(s) threatening his/her face. In the present study, the disagreements are expressed in bald strategies using 'not' and 'no' lexical items without any preface and/or explanation; hence, it is un-prefaced and ungrounded disagreements.

The two excerpts of bald, direct disagreements mentioned earlier, both expressed by the Javanese female students, are the only cases among many other cases of disagreements expressed using politeness strategies. The bald disagreements result in two responses. The first is a response from another student who questions the disagreement, and the second is ignoring from the two persons who are exchanging ideas. This but shows that Mori (1999), Pomerantz (1984), Sacks (1973), and Waring (2000 \& 2001) are correct when arguing that a disagreement is a dispreferred response; therefore, to express it people need to redress it with politeness strategies.

\section{Disagreeing by Acknowledging Peers}

Acknowledging peers means showing that the speaker (S)'s desires are similar to the addressee's wants in one way or another. The strategies are applied by attending to hearer $(\mathrm{H})$ 's points, intensifying opinions to $\mathrm{H}$, seeking agreement, stressing common ground, joking, indicating understanding of H's wants, offering another opinion, including both $\mathrm{S}$ and $\mathrm{H}$ in the activity, giving or asking for reasons, and showing appreciation while expressing disagreement. This is similar to Nathan et al.'s (2007) study that students appear to need a shared understanding to express substantive disagreement through divergent views. In the current study, disagreements expressed using these strategies are responded by acceptance, partial acceptance, support, no response/topic shift, laughter/acceptance, undetermined response, neutralizer from another participant, and defense.

Excerpt 4 shows partial acceptance to the disagreement expressed by acknowledging peers.

Excerpt $4(13 / 14)$

Ovi: Ya, first they ask the students to write essay on good teacher. So, a:: free response, free
response and then after that they develop, maybe they develop this free response into
questionnaire. Then, they give the questionnaire to the students, and then, this, this, I think
this's the real sample who has to choose from the questionnaire, maybe. Maybe, it's like that.
The essay:: These essays were then analyzed to find out how frequently different factors were
mentioned for each of these three aspects of culture of learning ((reading from page 86)).


Koko: $\quad$ Oka::y, ya, okay, but the sample in this case, the results of those questionnaire, in general, I

$\rightarrow \quad$ think, using the 5-point of the likert scale, here, on page <86> ya::, <starting from disagree, ya for example a five point scale, ya> (( Ovi is speaking to Ais, Ais agrees with her, and Koko writes the 5-points of the scale on board)) maybe very agree or <strongly disagree> ya, strongly disagree $<$ strongly disagree $>$. That's the likert scale. And also it's-a:::, it was effected part ( ) teachers, ya using chi-square, chi-square.

Excerpt 4 exemplifies partial acceptance of different stance expressed by acknowledging peers. The partial acceptance is signaled by the use of 'okay' in the first part of Koko's utterances followed by 'but...' phrase. This 'okay, but' pattern shows that the speaker accepts only some parts of the previous opinion.

\section{Disagreeing by Asserting Vulnerability}

The term 'asserting vulnerability' is borrowed from Waring (2001). She refers 'asserting vulnerability' to the kinds of utterances in which the speakers frame themselves as being vulnerably confused, uncertain, lost, not knowing, or admit that their arguments have been less than accurate, consistent, coherent, or plausible (p.39). In the current data, asserting vulnerability is realized by appealing and mitigating strategies. Appealing is applied to make minimal assumption about the addressee, while mitigating strategy is used to soften the disagreements so as to give the addressee an option whether to accept or refuse the disagreements, to minimize the threat, and to dissociate the addressee from a particular intrusion.

Disagreements expressed by asserting vulnerability are responded through acceptance, support, offering an account, support from another participant, neutralizer from another participant, undetermined response, support search, and refusal. An example of support from another participant as a response to this disagreeing strategy is shown in excerpt 5.

Excerpt $5(14 / 12)$

Koko: It's interesting actually, ya. When we talk about the uses of the findings, if we use the findings for
teaching, maybe, ya, maybe, we can say useless, far useless. But, when we talk about language in
terms of sociolinguistics perspective, you know that gender is one of the variables when we talk
about sociolinguistics. It's very important, I think, it shows how gender influence the development
in the civil society. When we talk about this, I think, people tend to make language, make language
into > what's that < into sssex, or gender, gender inclusive, in this case. You know, another people
not use chairman anymore, but chairperson. This this is the effect of this, this movement, I think.
That's when we look this in terms of linguistics, sociolinguistics, in this case. But, in terms of
teaching, yes, I do agree with Pak Adi we:::: if we want to relate this, maybe it is useless here. ...
Ya, Pak Joni.
First of all, I want to say that this article is hard to understand, ya. To me, but, I heard from your
explanation, then-a I come to ( ) in terms of the conclusion of this article. Ya, a: perhaps, I agree,
but not totally. And then-a:: because I see, I see, and we have to see this also that such phenomenon
Joni:
a:: first of all linguistic, in terms of morphology. I happen to read, but not finish yet, about
derivation ( ) cigarette....

In the excerpt, Koko disagrees with Adi who disagrees with the presenter, that is, Ovi. So, Koko's disagreement with Adi functions to support the presenter and the article being presented. Koko's disagreement with Adi is not responded to by Adi, instead, it causes Joni to support Koko and, automatically, the presenter. In showing his support, Joni first admits that the article is difficult to understand. This is to hint to his interlocutor that his opinion might be incorrect. After that, he continues his utterances by saying, "Ya, a: perhaps, I agree, but not totally." With this, he prepares his interlocutor to hear his forthcoming utterances that contain his own opinion which is different from that of the interlocutor. In so doing, he shows his support to the ideas opposed by Adi without damaging Adi's face.

Excerpt 6 contains a contribution from another participant to neutralize the disagreement between the speaker and the addressee.

Excerpt $6(12 / 13)$

Joni: But, I don't think it is (the main reason), ya. A: maybe it is ( ) a: a, a I, I believe what, believe Pak
Gunarwan, in some examples of a:: in terms of ( ) of using Indonesians instead of bahasa Inggris,
English. I think, thi's not a::, these are not English. Then, the a: this brings a clear effect to who's
writing that this contains. In terms of speaking, in terms of micro-politics, language itself, but, I don't
think economic reasons may ( ) the purpose of Indonesian as the ( ) of economic=
=So. To me I agree that economy or politics have much influence on the count, countries, global
countries who speak English, ya. We know that a: because these superpower countries, so, whether
their politics, whether their economics, they are super. Now, so, I agree with ( ) Pak Pak Adi that it
is because of that English becomes global. But, now, what can we do now for Indonesian people, ya?
It is impossible to us t become superpower. Even until, >I don't know $<$, how many more years. So,
you can add this, what, what, what the least thing that we can do and learn? This is the language, ya.
So that we may become global and other countries will know us as a country, that there's a country
named Indonesia. So, I think, I agree with Pak Gunarwan, at least, the least thing that we can do is
learn English, use English. I think that's the point Pak.

In the excerpt, Ais stands as an arbiter between Joni and Adi who disagree with one another. Ais's utterances neutralize the un-ratified disagreement between the two people. She mediates the different positions by mentioning the 
correct aspect of Adi's stance, "I agree that economy or politics have much influence on the count, countries, global countries who speak English, ya..." Besides mentioning the strength of Adi's position, she also reveals its flaws, "But, now, what can we do now for Indonesian people, ya? It is impossible to us $t$ become superpower..." She uses this citation to direct her interlocutor to a good point that makes her agree with the author, Gunarwan, who is represented by the presenter, that is, Joni, "So, I think, I agree with Pak Gunarwan, at least, the least thing that we can do is learn English, use English." Thus, the un-ratified disagreement between Adi and Joni is responded to by Ais with a mediating talk.

\section{E. Disagreeing Indirectly}

In expressing disgreement indirectly, a speaker says something which is more general or actually different from what he/she means. He/she leaves it to the addressee to decide how to interpret it. By applying this strategy, the speaker wants to express his/her disagreement, which is an FTA, but does not want to take the responsibility for doing the FTA. The students convey their disagreements without any disagreeing head act or with a disagreeing head act which is directed to someone who is absent during the discussion session. Among the responses to indirect disagreements are disagreement emphasis, defense with an account, and topic shift.

Excerpt 7 shows an indirect disagreement responded with stronger disagreement expressed by the addressee.

Excerpt $7(9 / 23)$

Adi:

Ais:
Adi:
Ais:
Adi:

So, the focus here is this. A:: for example, for pronunciation of dog, this is an example. The: Japanese student are exposed to another varieties. The word dog is not completely the same in pronunciation...((giving examples of Indonesian' and Dutch's pronunciation of dog)). So, in this case, according to that kind of model, it is very important to introduce the students with the varieties. In, in Indonesia, for example, I don't know how many varieties of English. We can, we can teach not by hiring the teachers from Philippine, or from Malaysia, but we introduce it to the students with the varieties of local= =even local

Local, for example, how Maduranese people speak English= $=$ Their English is different from our English, yes.

For example, I ( ) when I studied in S1. My friend was from Situbondo, in which there was a Maduranese school there. ...
21

In excerpt 7, Adi who is indirectly disagreed by Ais does not perceive that Ais's statement is an expression of disagreement. Therefore, he repeats Ais's word 'local' with the same word and adds an emphasis on it and further example of it which stresses the difference between his and Ais's stance, "Local, for example, how Maduranese people speak English." Adi does not realize that his utterance in turn 23 enlarges the gap between his and Ais's opinion because Ais expresses her disagreement in turn 22 indirectly through presupposition. In fact, Adi applies a different presupposition from that of Ais's. This is the consequence of the application of an indirect strategy. The speaker, in this case Ais, leaves it to the addressee, Adi, on how to interpret her disagreement. Therefore, when Adi keeps on standing on his own position, even, he stresses the different stance, Ais finally adjusts her stance to his position by saying, "Their English is different from our English, yes."

\section{DISCUSSION}

The data show that the worst response is apparent when the disagreement is expressed in an aggravating manner. There are three reasons why the aggravated disagreement results in a communication deadlock. The first is that maintaining the addressee's face does not always become the first concern of the speaker. Spencer-Oatey (2000) explains that there are four face orientations of conversation participants: rapport enhancement orientation (the want to support and increase harmonious relationship), rapport maintenance orientation (the want to safeguard and preserve relationship), rapport neglect orientation (a lack of interest in the quality of the relationship between the interlocutors), and rapport challenge orientation (the concern to challenge or break the harmonious relationship).

When we see the data in Excerpt 1, we recognize that when expressing his disagreement with Ovi, Edo goes back and forth applying different face orientations. In 26, Edo applies rapport maintenance orientation; he says 'Do you agree...' to maintain good relationship between them. In 28-36, Edo uses rapport neglect orientation and rapport challenge orientation. Edo challenges Ovi with his question, "Do we go together with those who are inferior?" and his statements, for instance, "Maybe it's you who are inferior, not all women," stressed by using the pointing of his finger to Ovi. In 34, Edo neglects Ovi's feeling of being pressed with his challenges by saying, "Bu, Ovi. I read from a: psikologi wanita, that's, that a discrimination exists because women treat men as different..." When the argument reaches its climax in which Ovi still persists her position inspite of Edo's challenges, Edo changes the face orientation of his utterances. He tries to improve and fix the relationship by humbling himself as stupid, “...this is is very stupid. $\underline{E d o}$ is very stupid, Bu Ovi." He applies rapport enhancement orientation. Hence, the data do not support Brown and Levinson's (1987, p. 61) politeness theory suggesting that it is generally “in every participant's best interest to maintain each others' face". It is obvious from the data that Edo chooses to challenge Ovi in purpose and holds the four face orientations back and forth. 
In Kakava's (2002, p. 1550-2) paper, disagreements expressed through provoked questions goes with or without endearment term. In the case of the use of endearment term, the figurative kinship term paidaki mou 'my little child' is uttered. In the data, the aggravated disagreement is expressed with respecting term of address 'Bu Ovi' and humbling oneself using 'this is is very stupid. Edo is very stupid'. The term of address 'Bu' in this excerpt is applied not in the strategic sense as that of Brown and Levinson's (1987, p. 183) negative politeness. 'Bu' is applied in any situation, including the situation in which they are involved in a heated argument as apparent in the excerpt.

Edo's way of asking questions prior to expressing his disagreement is the same as that of an attorney in a courtroom as documented in Drew's (1998). The attorney uses a series of questions to imply an inconsistency in a witness's story. The attorney asks questions to which he knows the answer. This is similar to Edo's questions that he asks to contest her. In fact, she does not have a good account to reject what is stated by Edo in the following turn, "Ya, then there is no discrimination, actually."

The second reason of the communication deadlock is that there is no mediator during the disputes. In this case, the presence of a mediator is in need. Had one of the participant served as a mediator, the communication breakdown would not have come into existence. A mediator is supposed to regulate the decision making procedure so as to empower the disputants to resolve their differences on their own (Jacobs, 2002). The mediator is neither judge nor advocate, but serves only to facilitate the discussion between the disputants, in this case, Edo and Ovi. In classroom discussions, this role is usually performed by a moderator. Since there is no moderator in the doctorate discussions, the role is vacant. Therefore, when the presenter has a dispute with the audience, no mediator can calm the situation and serve as the facilitator between the disputants.

Thus, to guarantee that the discussion process goes well, there should be a mediation process in the case of a dispute. The mediation process is widely described in terms of values such as self determination, private ordering, indigenously derived values, equality, open communication, cooperative dialogue, voluntary participation, or decision by consensus. Within this framework, the neutrality of the mediator is central to the mediation process (Jacobs, 2002). Neutrality covers the terms such as impartial, nonpartisan, equidistant, unbiased, fair, balanced, even-handed, unprejudiced, and equitable. In mediation, disputants usually argue, contradict, object, challenge, and, sometimes, openly disagree with one another on certain topics. On the contrary, mediator may not do the same things. The mediator should resist the impulse to agree or to disagree with one or the other party, to challenge or contradict, to refute or support certain position. If mediator was present in the disputes between Edo and Ovi, and he/she could persist on his/her neutrality, such a breakdown in communication as shown in 5.1 would not exist.

The third reason of the communication breakdown during the aggravated disagreement is that Ovi responds too seriously to Edo's challenge which is intended to tease her. She cannot manipulate and manage her feelings of being attacked. She bothers too much of Edo's judgment about her that makes her unable to realize that it is actually intended to make fun of her. This is possible because every person has certain desire to project certain image about him/herself which is sometimes not the quality that he/she has. When this desired image is destroyed by others, the person gets hurt. Hence, he/she tends to react defensively to the criticism that is congruent more with the private perception of him/herself but does not agree with the image that he/she wants to give of him/herself (Pan, 1992).

In short, the aggravated disagreement results in a frustration on the part of the addressee because of three reasons. The first is that the speaker does not always maintain the addressee's face. The second is that there is no mediator during the dispute, and the third is the fact that the addressee cannot manipulate and manage her own feelings of being attacked. The response to the aggravated disagreement in the form of communication deadlock cannot facilitate further learning from peers. Thus, it should be avoided and fixed for the sake of searching for a better understanding.

Unlike the aggravated disagreement, disagreements conveyed by acknowledging peers and asserting vulnerability may facilitate further learning. Acceptance, partial acceptance and support are positive responses shown by the addressee to disagreements expressed through peer acknowledgment. Disagreements through vulnerability assertion are also responded with some positive responses, that is, acceptance, support, offer of an account, support from another participant, and neutralizer from another participant. Acceptance and partial acceptance as responses show that the addressee is willing to learn from the speaker, thus, he/she revises his/her own position and is ready to listen from another party. Likewise, support to the disagreer is also a good attitude shown by the addressee that he/she is ready to evaluate him/herself and learn from others. Offering an account is also considered positive for learning since it means that the addressee is inviting the speaker to have a further dialogue which might open new possibilities for new perspectives. Support from another participant is a good attitude shown by another discussion participant that may lead to a further exchange of ideas. Neutralizer from another participant as a response to a disagreement can save the one who disagrees and another who is disagreed with from an unhealthy dispute. Thus, these kinds of responses may also facilitate learning.

These positive responses are not found as responses to disagreements expressed aggravatedly and baldly. Thus, learning is mostly facilitated by disagreements expressed through peer acknowledgment and vulnerability assertion. Therefore, the discussants are suggested to express their disagreement via peer acknowledgment and vulnerability assertion strategies.

Hence, the findings of the present research support the previous studies suggesting that a disagreement is a dispreferred response (Pomerantz, 1984; Mori, 1999; Waring, 2000 \& 2001). This shows that harmony is stressed by 
the students during the classroom discussions; therefore, when they should disagree with another party they do not only soften the disagreements, but also acknowledge another's point and indirectly state their different positions. They just cannot express their disagreements directly; they preface and conclude the difference in opinion by applying strategies that promote collaboration in search for better comprehension and harmony in interaction among the discussion participants. Therefore, when a disagreement is aggravated, a breakdown in communication occurs (such as that in excerpt 1).

The discussions occur in a doctorate classroom within a university in East Java, Indonesia. Four of the participants are Javanese, three other participants are Sumatranese, Ambonesse, and Kupangese. Among the Javanese students and non-Javanese students, there is no strategy typical for certain ethnic background. Aggravating, direct strategy is used by Edo who is an Ambonesse now working in Menado. The rests of the strategies, peer acknowledgment-direct strategy, vulnerability assertion-direct strategy, indirect strategy and mixed strategies are applied by both Javanese and nonJavanese students. Among the Javanese students, there is no uniform pattern of strategies applied in expressing disagreements. Ais, who is a native Malangese, and Tia, who grew up in Central Java, have a chance of applying baldon, direct strategies. Meanwhile, Ovi who is also a native Malangese cannot stand to be disagreed intensively by Edo. Hence, ethnicity does not seem to play significant roles in strategy choice by the students during disagreements; individuals' ways of speaking are more apparent. Errington's (1985, p. 2) and Kartomiharjdo’s (1981) statements that Indonesian people have experienced a 'Javanization' is not supported.

In the light of this view, the strategies applied by the students reflect the use of the strategies by Indonesian students regardless their ethnicity. In general, living in harmony is stressed in Indonesian society. As a collectivist society, the individuals in it are motivated to give priority to the goals of the collectives over their own personal goals (Triandis, 1995). Hence, the findings of the present study support the existing theory and research report that people's ways of speaking is influenced by values, norms and principles held by people in certain society (Chaika, 1982; Kartomihardjo, $1981 \&$ 1988; Zaid, 1999).

The findings also highlight the previous study on schema of group seminar presentation introduction of Indonesian students speaking in English conducted by Thaib (1999). In Thaib's study, it is apparent that when opening their presentation, the students do not immediately introduce the topic of presentation to the audience. Instead, they thank the moderator/lecturer, send prayer to God/prophet, give background information before introducing the topic. This is different from that of the Australian student presentations where the presenters directly introduce the topic at the very first part of their presentation. This shows that when speaking in English, the Indonesian students still use Indonesian rhetorical structure of presentation; they do not adopt the English rhetorical structure of presentation.

A similar finding was apparent in Agar's (1991) data. He found out that his Austrian-descendant subject, who spent his life in the United States, spoke fluently his ancestor's language in terms of grammar and lexical variety. However, his American culture was clearly reflected in his communication. Thus, a foreign language has its own meanings and grammatical constructions which can fit to the culture of its users (Malcolm, 1996).

The findings of the present study and those of Thaib (1999), Agar (1991) and Malcolm (1996) prove that acculturation is not an easy one to undergo, especially in the context in which the language used is a foreign language, and not a second language. People sometimes get stuck at a level of "functional competence" when they have to master a great deal of language items, yet, they have not reached or surpassed the "acculturation threshold", that is, a certain threshold of communicative competence (Acton \& de Felix, 1992, p. 21).

These strengthen what has been stated by Beardsmore (1982) that bilingualism and biculturalism do not have symmetrical relationship. He puts it in the following words:

It is perfectly feasible to learn a foreign language without acquiring any of the cultural attributes implicit in that language though the learner's resultant behaviour may appear somewhat strange to a native speaker of that language. Much of the friction across different linguistic communities can arise out of situations where speakers of two languages have acquired two sets of linguistic patterns but then proceed to use the second set with the cultural values of the first (Beardsmore, 1982, p. 20).

This means that the level of language acquisition does not always reflect the level of cultural acquisition. A bilingual person is not necessarily a bicultural individual.

\section{CONCLUDING REMARKS}

In summary, the politeness strategies applied by the doctorate English Program students in expressing their disagreements are influenced by collectivists' principles which emphasize harmony. Although the students speak English, their politeness strategies are not adopted from the English politeness principles. The politeness strategies applied are influenced by the cultural values existing in the collectivist society. Hence, becoming a bilingual is not necessarily becoming a bicultural, especially, in the context of a foreign language.

\section{REFERENCES}

[1] Acton, W. R. \& de Felix, J. W. (1992). Acculturation and mind. In J.M. Valdes (Ed.). Culture bound: Bridging the cultural gap in language teaching (pp. 20-32). Cambridge: Cambridge University Press.

[2] Agar, M. (1991). The biculture in bilingual. Language in Society, 20,167-181. 
[3] Atkinson, J. M. \& Heritage, J. (1984). Structures of social action: Studies in conversation analysis. Cambridge: Cambridge University Press.

[4] Basturkmen, H. (2002). Negotiating meaning in seminar-type discussion and EAP. English for Specific Purposes, 21, $233-242$.

[5] Beardsmore, H. B. (1982). Bilingualism: Basic principles. Clevedon: Tieto Ltd.

[6] Blum-Kulka, S., Blondheim, M. \& Haconen, G. (2002). Traditions of disputes: from negotiations of Talmudic texts to the arena of political discourse in the media. Journal of Pragmatics, 34, 1569-1594.

[7] Brown, P. \& Levinson, S. (1987). Politeness: some universals in language use. Melbourne: Cambridge University Press.

[8] Chaika, E. (1982). Language, the social mirror. Rowley: Newbury House Publishers, Inc.

[9] De Klerk, V. \& Hunt, S. (2000). Discourse domination? The role of gender in seminar interaction. Southern African Linguistics and Applied Language Studies, 18, 73-87.

[10] Drew, P. (1998). Contested evidence in courtroom cross-examination: The case of a trial for rape. In P. Drew \& J. Heritage (Eds.), Talk at work (pp. 359-417). Melbourne: Cambridge University Press.

[11] Errington, J. (1985). Languages and social change in Java: Linguistic reflexes of modernization in a traditional royal polity. Athens: Monograps in International Studies.

[12] Grice, P. (2001). Logic and Conversation. In Martinich, A.P. The Philosophy of Language. Oxford: Oxford University Press.

[13] Heritage, J. \& Atkinson, J.M. (1984). Introduction. In J.M. Atkinson \& J. Heritage (Eds.), Structures of social action: Studies in conversation analysis (pp. 1-15). Cambridge: Cambridge University Press.

[14] Hutchby, I. \& Wooffit, R. (1998). Conversation analysis: Principle, practices, and applications. Cambridge: Blackwell Publisher, Ltd.

[15] Jacobs, S. (2002). Maintaining neutrality in dispute mediation: Managing disagreement while managing not to disagree. Journal of Pragmatics, 34, 1403-1426.

[16] Kakava, C. (2002). Opposition in modern Greek discourse: Cultural and contextual constraints. Journal of Pragmatics, 34, $1537-1568$.

[17] Kartomihardjo, S. (1981). Ethnography of communicative codes in East Java. Canberra: The Australian National University.

[18] Kartomihardjo, S. (1988). Bahasa cermin kehidupan masyarakat. Jakarta: Departemen Pendidikan dan Kebudayaan.

[19] Levinson, S.C. (1983). Pragmatics. London: Cambridge University Press.

[20] Malcolm, I.G. (1996). One language two cultures: Implementing bi-dialectal education. In J.E. James (Ed.). The languageculture connection. (pp. 123-135). Singapore: SEAMEO RELC.

[21] Medina, J. (2010). Wittgenstein as a rebel: Dissidence and contestation in discursive practices. International Journal of Philosophical Studies, 18(1), 1-29.

[22] Mori, J. (1999). Negotiating agreement and disagreement in Japanese: Connective expressions and turn constructions. Amsterdam: John Benjamins Publishing Company.

[23] Nathan, M. J., Eilam, B. \& Kim, S. (2007). To disagree, we must also agree: How intersubjectivity structures and perpetuates discourse in a mathematics classroom. The Journal of the Learning Sciences, 16(4), 523-563.

[24] Pan, D. (1992). Proceedings from FASS symposium on Teaching and Learning at the National University of Singapore, 27-28 October 1992. Giving and receiving feedback and criticism: Essential skills for professors. Singapore: NUS.

[25] Pomerantz, A. (1984). Agreeing and disagreeing with assessments: some features of preferred/dispreferred turn shapes. In J.M. Atkinson \& J. Heritage (Eds.), Structures of social action: Studies in conversation analysis (pp. 57-101). Cambridge: Cambridge University Press.

[26] Rohmah, Z. (2003). Male-female talk in summer curriculum workshop. Unpublished Research Report. Malang-Urbana: Fulbright Commission.

[27] Sack, H. (1973). On the preferences for agreement and contiguity in sequences in conversation. public lecture at the Linguistic Institute, University of Michigan. In G. Button \& J.R.E. Lee. (Eds.), Talk and organization (pp.54-69). Clevedon: Multilingual Matters.

[28] Sack, H. (1984). Notes on methodology. In J.M. Atkinson \& J. Heritage (Eds.), Structures of social action: Studies in conversation analysis (pp. 21-27). Cambridge: Cambridge University Press.

[29] Schegloff, E. A. (1984). On some questions and ambiguities in conversation. In J.M. Atkinson \& J. Heritage (Eds.), Structures of social action: Studies in conversation analysis (pp. 28-52). Cambridge: Cambridge University Press.

[30] Spencer-Oatey, H. (2000). Culturally speaking: Managing rapport through talk across cultures. New York: Continuum.

[31] Thaib, R. (1999). Schema of group seminar presentations and rhetorical structure of presentation introductions: A cross-cultural study of Indonesian and Australian students in university academic settings. Asian Englishes, 2(1):66-89.

[32] Tracy, K., \& Baratz, S. (1993). Intellectual discussion in the academy as situated discourse. Communication Monograph, 13, 301-320.

[33] Tracy, K., \& Carjuzaa, J. (1993). Identity enactment in intellectual discussion. Journal of Language and Social Psychology, 12(3), 171-194.

[34] Triandis, H.C. (1995). Individualism and collectivism. Boulder: Westview Press, Inc.

[35] Tuval-Mashiach, R. \& Shulman, S. (2006). Resolution of disagreements between romantic partners, among adolescents, and young adults: Qualitative analysis of interaction discourses. Journal of Research on Adolescence, 16(4), 561-588.

[36] Viechnicki, G.B. (1997). An empirical analysis of participant intentions: discourse in a graduate seminar. Language \& Communication, 17(2): 103-131.

[37] Waring, H. Z. (2000). Discourse strategies used in seminar discussion: a conversation analytic approach. Ann Arbor: UMI.

[38] Waring, H. Z. (2001). Balancing the competing interests in seminar discussion: peer referencing and asserting vulnerability. Issues in Applied Linguistics, 12(1), 29- 50.

[39] Waring, H. Z. (2002a). Displaying substantive recipiency in seminar discussion. Research on Language and Social Interaction, $35,453-479$.

[40] Waring, H. Z. (2002b). Expressing noncomprehension in a U.S. graduate seminar. Journal of Pragmatics, 34, $1711-1731$. 
[41] Webber, P. \& Kyriacou, K.A. (2008). The interpretation of conflict and negotiation in post-paper presentation discussions. Journal of Applied Linguistics, 5(1), 81-112.

[42] Wei, L. (2002). 'What do you want me to say?' On the conversation analysis approach to bilingual interaction. Language and Society, 31:159-180.

Zuliati Rohmah is a faculty member at the English Department IAIN Sunan Ampel Surabaya, Indonesia. She earned her doctoral degree in English Teaching from the State University of Malang. She has been active in providing training for teachers for the last five years. Currently, she is a Humphrey Fellow at the University of Minnesota, Twin Cities, USA. 